\title{
PRAIRIE POTHOLES AND SWALLOWS: A CASE FOR CONSERVATION IN PRAIRIE AGRICULTURE
}

Andrew S. Elgin

andrew.elgin@usask.ca

Wetlands, ponds, potholes, or sloughs - whichever name is used, millions of wetland basins are integral features on the northern prairie landscape. Though it is likely most readers of this article will be familiar with prairie pothole wetlands and their ecological importance, I would be remiss in failing to provide some background. The prairie potholes are glaciallyformed basins that can be filled by precipitation, primarily snowmelt, forming wetlands which may contain ephemeral to permanent ponds (i.e., the open water within a wetland). ${ }^{1}$ Prairie wetlands and associated ponds provide important habitat for many species of flora and fauna, including a diversity of birds; however, the prairie landscape has been heavily altered by human settlement and extensive agricultural land use, including the drainage and conversion of wetland basins. 2,3 Estimates suggest that 40 to 70 per cent of historical prairie wetland basins have been lost in Canada, though only rough estimates of wetland loss can be inferred from the limited historical information. ${ }^{2}$ Nevertheless, remaining prairie wetlands can act as important biodiversity "hotspots" on the predominantly agricultural landscape of the Prairies. ${ }^{4,5}$

Among the birds that make use of wetland ponds are Tree Swallows (Tachycineta bicolor), which are a member of the foraging guild known as "aerial insectivores," a group of birds that capture insect prey while in flight. In general, Tree Swallows often feed on aquatic insects emerging from water, including wetland ponds, and aquatic insects are similarly prevalent in the diet of Tree Swallows nesting at sites with wetland ponds in southcentral Saskatchewan. 6,7 Because Tree Swallows have somewhat "flexible" diets, they may "switch" to feeding on terrestrial insects in areas where aquatic insects are less available..$^{8-10}$ Still, such a dietary switch is perhaps not without cost. Recent evidence suggests that not only are aquatic insects a source of energy for swallows, but these insects may also act as an important source of essential nutrients. In particular, aquatic insects can act as a dietary source for omega-3 longchain polyunsaturated fatty acids, which may increase nestling Tree Swallow growth rates. ${ }^{11}$ Similarly, greater availability of aquatic insects has been associated with improved fledging success for Tree Swallow nestlings. ${ }^{12}$ These findings collectively suggest that aquatic habitats, such as prairie wetland ponds, might be critical foraging areas for swallows provisioning their nestlings with insects as food.

My graduate research focused on the importance of prairie ponds as foraging habitat and a source of aquatic insect prey for Tree Swallows breeding in nest box colonies at four agricultural sites in southcentral Saskatchewan. Additionally, we examined whether the swallows at these sites were being exposed to agricultural pesticides commonly used on the Prairies, representing a possible negative impact on swallows' diet quality. One of these four study sites, at the St. Denis National Wildlife Area, was primarily dominated by grassland; two sites near Colonsay and Burr were dominated by cropland; and one site near Humboldt was "mixed," with both non-crop cover and cropland near swallow nest boxes. The "availability" of wetland ponds also varied among sites; in particular, one cropland site near Burr had lower water cover than the other study sites, which was in part attributable to more extensive drainage. These study sites, with differing agricultural land cover (i.e., primarily grassland and semi-natural areas, cropland, or both) and varied densities of prairie wetlands, formed the backdrop for several research questions.

Prior results have suggested Tree Swallows on prairie sites were feeding primarily on aquatic insects that emerge from ponds, ${ }^{6}$ but it was not entirely clear whether swallows were relying on the ponds as sites to capture prey. Are breeding swallows taking advantage of ponds as areas to easily capture these newly emerged aquatic insects, or are they simply capturing aquatic insects that have traveled across the landscape? After all, swallows' insect prey have wings, too. To investigate swallow habitat use, we tracked 24 adult female Tree Swallows over the course of a day (from 05:00 $\mathrm{h}$ to 22:00 h local time) using miniature GPS tags (Figure 1), weighing $\sim 1.2 \mathrm{~g}$ and removed after tracking. The data gleaned from these tags suggested that swallows were selecting ponds as foraging areas more than terrestrial habitats (primarily grassland or cropland); that is, swallows appeared to use wetland ponds disproportionately to pond availability on the landscape, in patterns consistent with foraging.

We next asked whether there were differences in swallow diet quality attributable to the availability of wetland ponds and local agricultural practice; namely, 


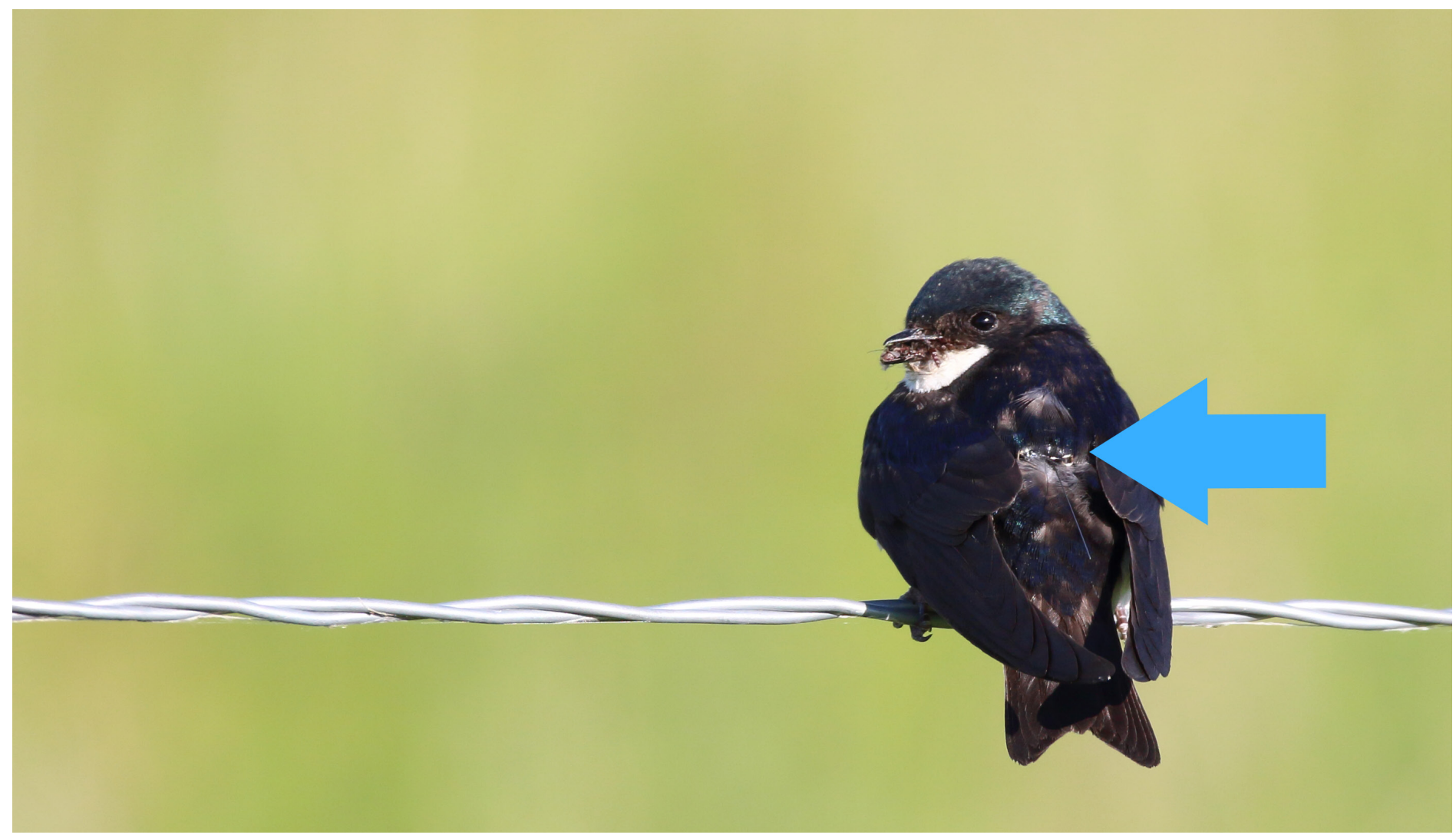

FIGURE 1: A female Tree Swallow, equipped with GPS tag (blue arrow), prepares to deliver insect prey to her nestlings. Photo credit: Andrew Elgin.

we examined nestling swallows' omega-3 long-chain polyunsaturated fatty acid "status" and exposure to neonicotinoid insecticides, among other pesticides, using small blood samples and diet sampling. We focused on exposure to neonicotinoid insecticides, in part, because they are widely used in Prairie Canada as a prophylactic seed treatment, and consequently, have been frequently detected in wetland ponds. ${ }^{13}$ Our results suggested a pattern of lower omega-3 status in nestlings sampled from the most drained site relative to nestlings sampled at the other sites. More explicitly, these results suggested that wetland ponds (and presumably, aquatic insects) contribute to enhancing nestling swallows' diet quality, regardless of local agricultural practice (i.e., cropping or grazing). Interestingly, and perhaps concerningly, we found that blood plasma from all sampled nestlings suggested exposure to the neonicotinoid insecticide imidacloprid. Although there were some differences in plasma concentrations among sites (nestlings at the Humboldt site tended to have greater plasma imidacloprid than those at the St. Denis or Colonsay site), these differences were not clearly related to local cropping. On the other hand, the concentration of another neonicotinoid, clothianidin, tended to be greater in sampled nestlings on sites with cropland near nests compared to the grassland-dominated site. We further confirmed that these neonicotinoid insecticides, and several other pesticides, were present in some insect prey delivered to nestlings, strongly suggesting that these pesticide exposures were attributable to dietary intake. Though it is not yet clear whether swallows' exposure to various pesticides has negative impacts, such as impacts on growth or other toxic effects, these results confirmed that even insectivorous birds are among the non-target animals which may experience widespread exposure to neonicotinoids, among other pesticides.

Overall, the results of my thesis research support the retention and restoration of prairie ponds to support swallow populations in the Prairies. Our results suggested that, for Tree Swallows, wetland ponds appear to be critical foraging areas and a source of nutrientrich aquatic insect prey. However, our findings also confirmed Tree Swallows are among several recently documented non-target organisms which are exposed to neonicotinoid insecticides, in addition to other pesticides. The apparent pervasiveness of neonicotinoids, along with their possible effects on non-target organisms, calls into question their extensive prophylactic use. From a personal perspective, I would suggest that these results argue for an improved 
balance between human needs and biodiversity conservation in the Prairie Pothole Region. Like prairie ponds, agriculture is now also a fundamental feature of the Prairie landscape, giving rise to social and economic factors (including the livelihoods of farmers) which must also be considered. In my view, neither drainage nor pesticides is the enemy of conservationists. I suggest it is rather the thoughtless application of these and other practices, without consideration of necessity or impacts on nature, which represents the primary obstacle to biodiversity conservation in agricultural landscapes. Though I would not claim to have the ultimate solutions to these problems, I do believe we are all better served by striving toward and promoting a greater balance between the needs of humankind and the preservation of natural ecosystems.

\section{Acknowledgements}

Thanks to the farmers and landowners for allowing access to their land. Thanks to my supervisors, Dr. Christy Morrissey and Dr. Bob Clark, for their extensive support, and to numerous field technicians and others who helped to make this work possible. Funding was provided by grants from the Natural Sciences and Engineering Research Council of Canada (NSERC), Environment and Climate Change Canada (ECCC), and scholarship funding from the University of Saskatchewan and Nature Saskatchewan, whose support I cherish.

1. van der Kamp G, Hayashi M, BedardHaughn A, Pennock D (2016) Prairie Pothole Wetlands - Suggestions for Practical and Objective Definitions and Terminology. Wetlands 36:S229-S235.

2. Dahl TE, Watmough MD (2007) Current approaches to wetland status and trends monitoring in prairie Canada and the continental United States of America.
Canadian Journal of Remote Sensing 33:S17S27.

3. Bartzen BA, Dufour KW, Clark RG, Caswell FD (2010) Trends in agricultural impact and recovery of wetlands in prairie Canada. Ecological Applications 20:525-538.

4. Shutler D, Mullie A, Clark RG (2000) Bird Communities of Prairie Upland and Wetlands in Relation to Farming Practices in Saskatchewan. Conservation Biology 14:1441-1451.

\section{Mineau P, Mclaughlin A (1996)}

Conservation of biodiversity within Canadian agricultural landscapes: integrating habitat for wildlife. Journal of Agricultural and Environmental Ethics 9:93-113.

6. Michelson Cl, Clark RG, Morrissey CA (2018) Agricultural land cover does not affect the diet of Tree Swallows in wetland-dominated habitats. The Condor: Ornithological Applications 120:751-764.

7. Winkler DW, Hallinger KK, Ardia DR, Robertson RJ, Stutchbury BJ, Cohen RR (2020) Tree Swallow (Tachycineta bicolor), version 1.0, in Birds of the World (Poole, A. F., Ed.), https://doi.org/10.2173/bow. treswa.01. Cornell Lab of Ornithology, Ithaca, New York.

8. Mengelkoch JM, Niemi GJ, Regal RR (2004) Diet of the nestling tree swallow. The Condor 106:423-429.

9. McCarty JP, Winkler DW (1999) Foraging ecology and diet selectivity of tree swallows feeding nestlings. The Condor 101:246-254.

10. Johnson ME, Lombardo MP (2000) Nestling Tree Swallow (Tachycineta bicolor) Diets in an Upland Old Field in Western Michigan. American Midland Naturalist 144:216-219.

11. Twining CW, Brenna JT, Lawrence $P$, Shipley JR, Tollefson TN, Winkler DW (2016) Omega-3 long-chain polyunsaturated fatty acids support aerial insectivore performance more than food quantity. Proceedings of the National Academy of Sciences 113:1092010925.

12. Twining CW, Shipley JR, Winkler DW (2018) Aquatic insects rich in omega-3 fatty acids drive breeding success in a widespread bird. Ecology Letters 21:1812-1820.

13. Main AR, Headley JV, Peru KM, Michel NL, Cessna AJ, Morrissey CA (2014) Widespread Use and Frequent Detection of Neonicotinoid Insecticides in Wetlands of Canada's Prairie Pothole Region. PLOS ONE 9.

\section{POETRY}

\section{The Circle}

wheatgrass leaves individually

illuminated by the sun

green to gold to brown

senescence writ large

substrate for the green........

Ross Macdonald

P.O. Box 59

Lake Alma, SK SOC 1M0

ross.98ranch@xplornet.com

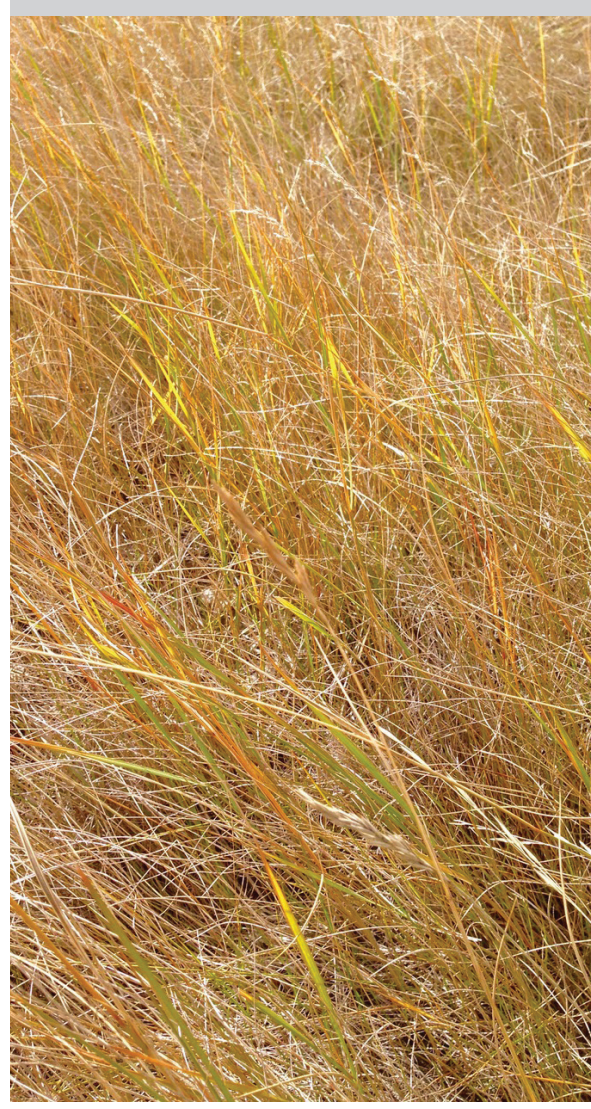

